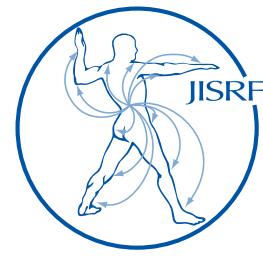

\title{
Biomechanical Alignment of Main Wear- Pattern on MOM Total Hip Replacement
}

\author{
Burton $P^{1}$, Medina $E^{2}$, Burgett-Moreno $M^{3}$, Donaldson $T^{3}$, Clarke $I^{3}$
}

\begin{abstract}
In the majority of retrievals, femoral heads and cups are sent for analysis with no designation as to positioning in-vivo. In addition, when patients retain the femoral prosthesis, evidence of neck impingement damage is lost. In this case report we studied head and cup wear-patterns and stripe damage in a novel case that included a large diameter metal-on-metal THA that was retrieved with the head still fused to the stem. This provided anatomical positioning of head wear-pattern and stripe damage as represented by the orientation of the femoral stem in radiographic images. We investigated (1) size, shape and location of head and cup wear-patterns, (2) cup-to-stem impingement damage, and (3) head stripe-wear. The head wear-pattern was elliptical in shape, $40 \mathrm{~mm}$ diameter with area covering $2200 \mathrm{sq} . \mathrm{mm}$. Its hemispherical ratio was 56\% with aspect ratio 1.2 and typical of large-diameter MOM retrievals. Wear-pattern extended from $12^{\circ}$ above superior head-margin to approximately $40^{\circ}$ inferior to polar axis. Centroidal vector in coronal plane was $13^{\circ}$ posterior to polar axis and in transverse plane was $19^{\circ}$ superior to polar axis. These vector data corresponded well with biomechanical predictions of resultant load axes in gait studies. Stripe damage was identified on the head, and the cup rim could thereby be aligned to verify neck impingement and also head subluxation mechanisms. Cup wear-pattern was not centrally contained, indicating this patient had experienced repetitive edge-wear during gait. Thinning of the cup rim by $350-400 \mu \mathrm{m}$ indicated that posterior impingement with repetitive anterior subluxation of the head had created this edge-wear.
\end{abstract}

Keywords: wear-pattern, alignment, metal-on-metal, heads, total hip

Level of Evidence: AAOS Therapeutic Level IV

\section{Introduction}

Contemporary MOM bearings offered perceived benefits of lower wear compared to metal-on-polyethylene and with use of large-diameter heads offered additional benefits of greater motion and superior stability $[1,2]$. With a variety of designs and both positive [3-5] and negative reports [6-10] now emerging with regard to MOM in both total hip arthroplasty (THA) and resurfacing arthroplasty (RSA), many studies have focused on issues regarding
1 Arrowhead Orthopedics, 1901 West Lugonia Avenue, Redlands, CA 92374 US

2 Instituto Nacional de Rehabilitación, Calz. México Xochimilco 289, Tlalpan, Arenal de Guadalupe, 14389 Ciudad de México, D.F., MX

3 Donaldson Arthritis Research Foundation, 900 E Washington St, Ste 200, Colton, CA 92324 US

(C) 2015 Burton, Medina, Burgett-Moreno, Donaldson, Clarke. All rights reserved Authors retain copyright and grant the journal right of first publication with the work. Reconstructive Review follows the Creative Commons Attribution-NonCommercial CC BY-NC. This license allows anyone to download works, build upon the material, and share them with others for non-commercial purposes as long as they credit the senior author, Reconstructive Review, and the Joint Implant Surgery \& Research Foundation (JISRF). An example credit would be: "Courtesy of (senior author's name), Reconstructive Review, JISRF, Chagrin Falls, Ohio". 
metal alloys, cup design, surgical positioning [11-13] and effects of "edge loading" [7,9,14-19].

From studies of retrieved ceramic-on-ceramic (COC) bearings it was apparent that there were two types of wear patterns in THA. The anticipated 'normal' mode of everyday activities $[20,21]$ created more or less circular wear patches on the head and inside the cup $[22,23]$. However, COC cases with 1 to 22 years follow-up also revealed evidence of a crescent-shaped type of stripe wear across femoral heads and around the rims of ceramic cups [22,2427]. The latter wear damage was attributable to edge-wear of ceramic cups. Retrieval studies of large diameter MOM bearings also revealed these normal wear patterns, termed main wear zones (MWZ), on both heads and cups [28-30]. Evidence of stripe wear mechanisms appeared to indicate 3rd-body wear damage, plastic deformation due to rim impingement, or both phenomena [31,32].

In the majority of retrieval cases, retrieved femoral heads and cups are sent for analysis with no designation as to their original anatomical positioning. In addition, when patients retain the femoral prosthesis, the signs of impingement damage on femoral necks are lost. We therefore sought evidence of wear patterns and stripe wear mechanisms in a large diameter THA that was retrieved with the head still fused to the femoral stem. This gave us the anatomical position of the femoral head as represented by the orientation of the stem. We investigated (1) size, shape and location of the MWZ areas on the femoral head and cup, (2) damage from cup-to-stem impingement, and (3) stripe damage.

\section{Consent}

The patient signed an IRB approved consent allowing review of her records and analysis of her hardware as well as verbally consented to publication of her case.

\section{Materials and Methods}

A primary MOM total hip was performed in February 2008 on a 35 year old female patient (BMI 38.5) for avascular necrosis. Medical history included a single seizure associated with a febrile illness seven years prior to her hip replacement surgery. X-ray images demonstrated acetabular cup position with $55^{\circ}$ inclination and $39^{\circ}$ anteversion estimated from the AP pelvis radiograph (Figure 1). Eight months postoperatively the patient developed headaches, memory loss, vertigo, and aura-like symptoms which progressed to seizures and she consulted with a neurologist. At 12 months postoperatively, the patient presented with progressive hip pain and sounds of "popping", gross creak-

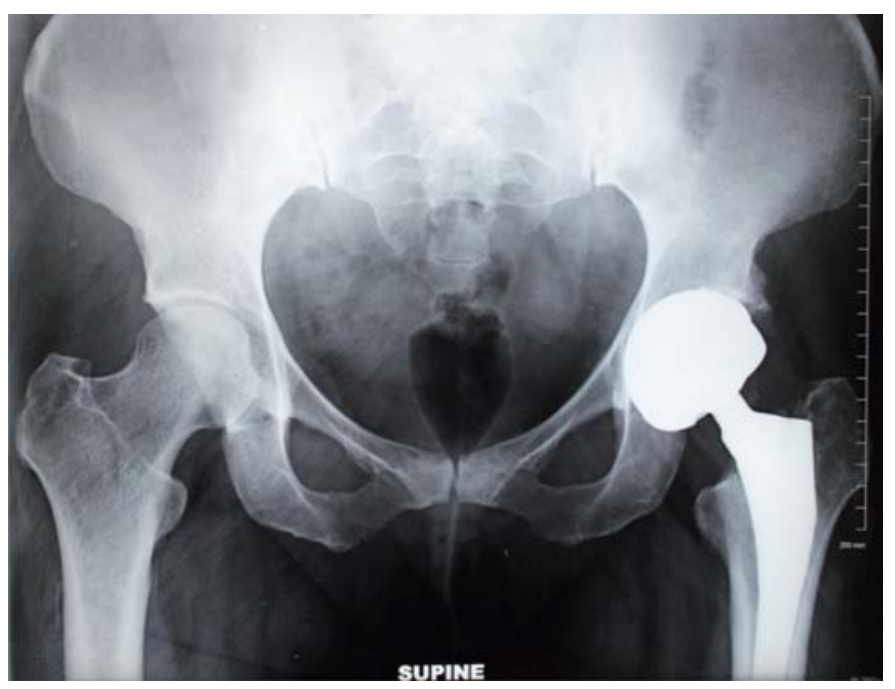

Figure 1: Pre-revision AP pelvis of left hip prosthesis. Cup inclination was measured as $55^{\circ}$ and anteversion calculated as $39^{\circ}$ using this view

ing, and crepitus sensations with motion. Blood samples were collected at this time, revealing her serum cobalt level was $126.8 \mathrm{ppb}$ and her serum chromium level was 64 $\mathrm{ppb}$. Her ultrasound showed a small fluid collection along the femoral head and neck $(2.4 \times 3.9 \mathrm{~cm})$ and the echocardiogram was positive for mild mitral and trace tricuspid regurgitation. There was no change in component position and there was no evidence of loosening or osteolysis.

Revision surgery was performed at 32 months postoperatively (November 2010). At surgery, upon entering the hip capsule a dark, serous fluid was observed along with synovitis. The implants were well fixed. Several attempts were made to remove the femoral head in order to retain the well-fixed stem. However, the head appeared fused to the trunnion and a femoral osteotomy was performed to remove the stem. Synovial tissue and capsule were sent to pathology along with the dark, serous fluid for culture. The pathologist reported all cultures were negative and the histology indicated an inflammatory response consistent with aseptic lymphocyte-dominated vasculitis-associated lesion (ALVAL).

Following revision, the patient's mental status normalized and headaches and seizures stopped. Her serum cobalt level gradually declined and 11 months after revision it measured $1.1 \mathrm{ppb}$. The patient has had some persistent hip pain since the revision surgery, possible related to her lumbar spine disease.

Retrieved components included a $50 \mathrm{~mm}$ Magnum head (modular -3mm taper adapter), a M2a Magnum cup (56mm outer diameter), and a lateralized Taperloc stem (Porous coated, size 10 x 140mm, Biomet, Warsaw, IN). The components were studied visually by stereo-microscopy, white-light interferometery (WLI: NewView 600 Zygo Corp.), and scanning electron microscopy (SEM: EVO 
MA 15, Zeiss). Surface features were graded visually and verified by stereo-microscopy. Wear patterns (MWZ) were measured by included angles and both MWZ area and hemispherical-area ratio (\%Hemi) were calculated [31]. Centroidal vectors were calculated by measuring the arcs of the wear pattern in multiple views (Figure 2). The cup MWZ extended up to the cup rim, representative of 'edge-

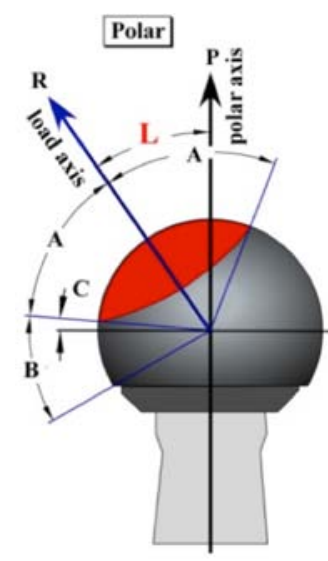

a) AP-view of Explant

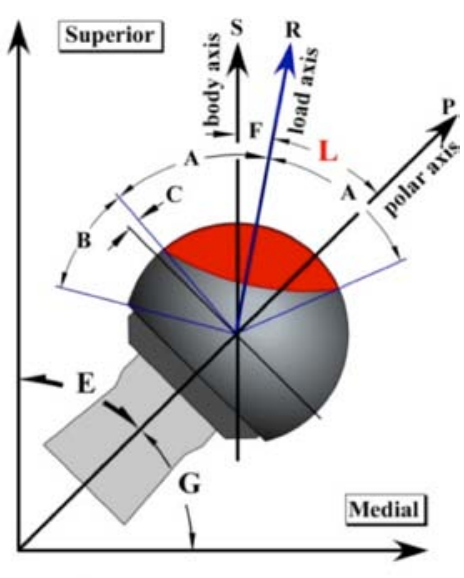

b) Viewed antero-posterior
Figure 2: Representative model to calculate the vectors and the axis on the head.

wear', and assessed by the rim-bearing angle. SEM and energy-dispersive spectroscopy (EDS: Bruker, Inc.) were used to investigate surface details and possible material transfer.

\section{Results}

This retrieval was novel because the fused head revealed the exact orientation of the MWZ in vivo. This was elliptical in shape and extended from $12^{\circ}$ above the superior edge to approximately $40^{\circ}$ inferior of the polar axis. The MWZ was approximately $40 \mathrm{~mm}$ in diameter, with $2200 \mathrm{~mm}^{2}$ area. The MWZ hemispherical ratio was $56 \%$ with aspect ratio 1.2, typical of MOM retrievals [31]. In the coronal plane, the centroidal vector was approximately $13.3^{\circ}$ posterior to the polar axis and in the transverse plane, the centroidal vector was approximately $18.8^{\circ}$ superior to the polar axis (Figure 3).

The cup had not been marked at revision so the orientation in vivo was unknown. The orientation was estimated based on experience with our previous study of $60 \mathrm{MOM}$ retrievals [31]. The cup MWZ extended up to the rim over a $157^{\circ}$ arc (Figure 4). It descended approximately $36 \mathrm{~mm}$ into the cup, and covered an area of $1275 \mathrm{~mm}^{2}$. Thinning of the cup rim and loss of the cup 'bevel' was identified in a $90^{\circ}$ arc inferiorly (Figure 4).

Stripe wear was identified on the femoral head and the cup rim could be aligned with to verify both neck impinge-

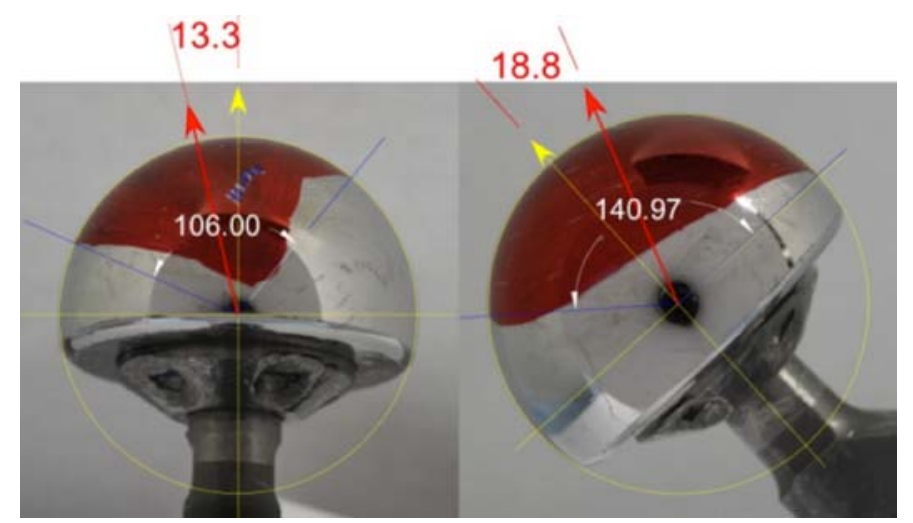

Figure 3: Coronal and transverse views of fused femoral head to calculate centroidal vectors of $M W Z$.

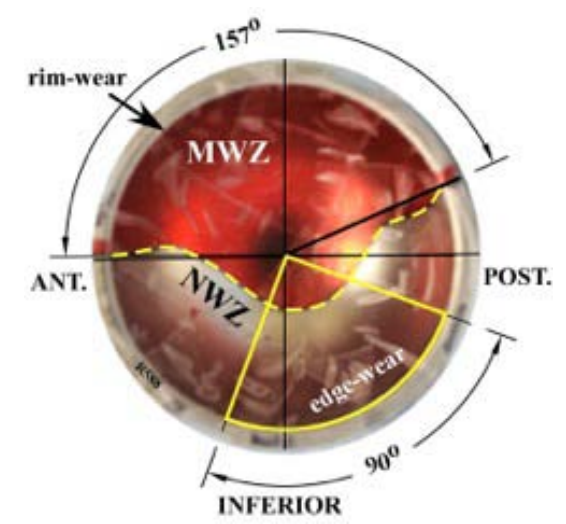

Figure 4. Cup MWZ had 157o arc across the superior rim, while thinning of cup edge extended over $90^{\circ}$ arc inferiorly.

ment and head subluxation mechanisms. Although stripe wear was readily identified by SEM (Figure 5), details of head wear-patterns were greatly obscured by metallic contaminating layers. EDS-imaging identified $\mathrm{Fe}$ and $\mathrm{Ni}$ elements, typical of stainless-steel instruments used during the revision operation (figure 6). Circumferential markings on the posterior femoral neck represented damage caused by the cup rim during impingement (Figure 7). Thinning of the cup rim by $350-400 \mu \mathrm{m}$ (Figure 4 ) indicated that posterior impingement resulted in repetitive anterior subluxation of the femoral head, thereby creating edge wear.

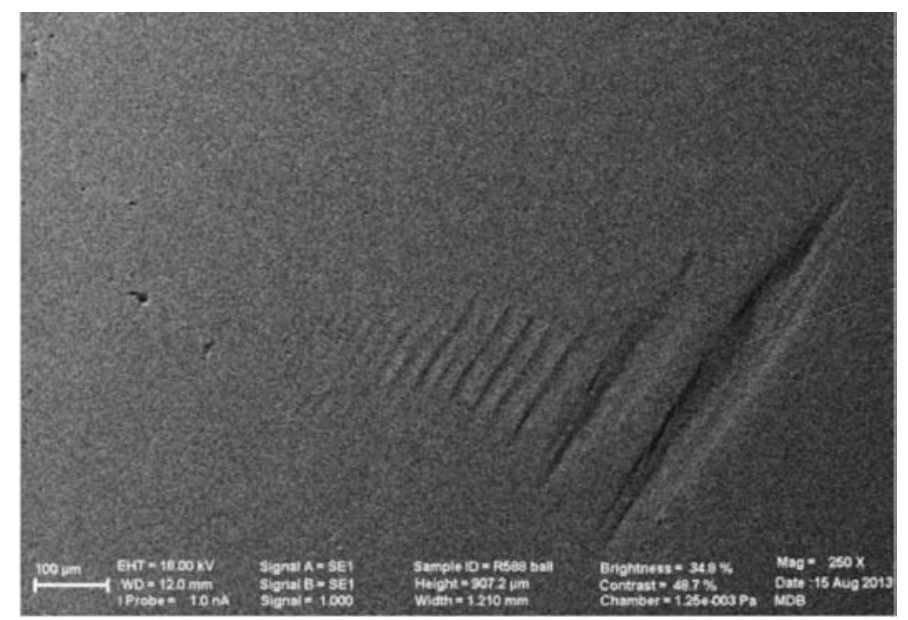

Figure 5. SEM imaging of approximately $50 \mu \mathrm{m}$ grooves in head's polar region. 


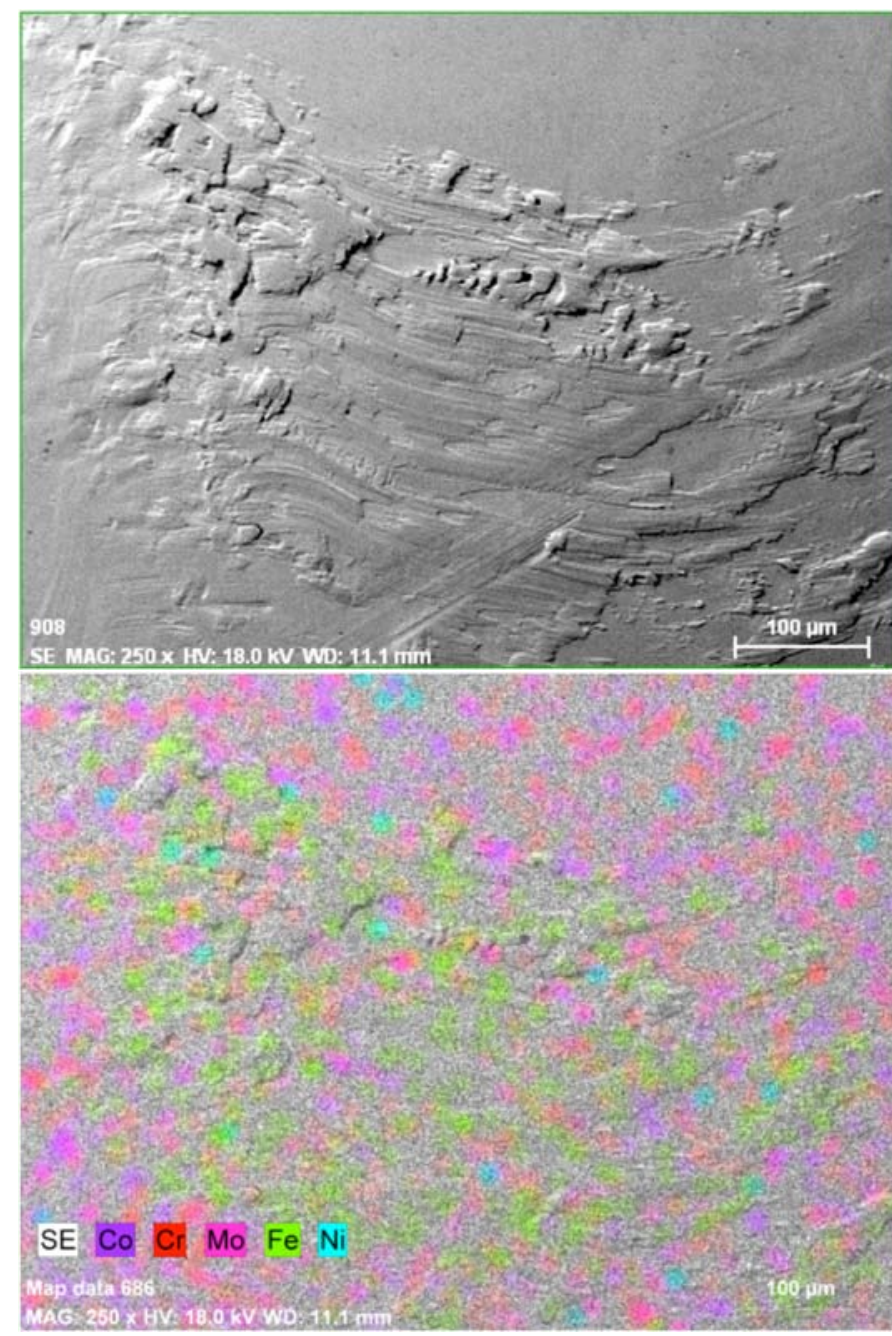

Figure 6: SEM image of contamination of the CoCr head. EDS identified iron and nickel, indicating stainless steel from instruments used during surgery.

\section{Discussion}

Wear analysis can be severely limited by the fact that retrieved bearings seldom come marked to identify positioning in vivo [33]. With MOM bearings it was possible to identi-

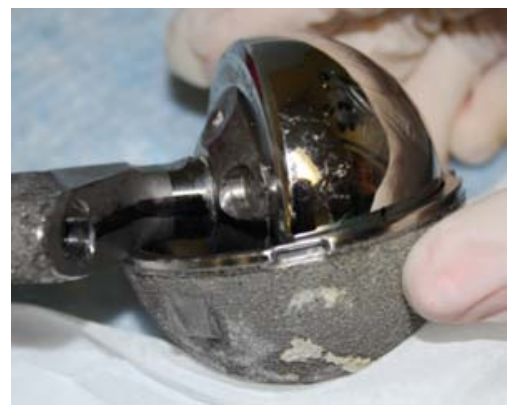

Figure 7. Impingement of cup on neck was verified by aligning cup rim to the circumferential neck markings and noting the rim was juxtaposed to polar stripes on head. fy the normal wear patterns in hip simulator studies [34]. Our underlying assumption for the modular femoral heads that came with no markings was that the narrowest margin between the wear pattern and the base of the femoral head represented the superior site (Fig. 3b). We applied this method to MOM retrieval studies to identify the wear patterns created in vivo and thereby deduce the implant orientations $[31,35]$. This also became a prerequisite for determining stripe wear locations produced on femoral heads, where the cups reached extremes of hip motion. This $50 \mathrm{~mm}$ MOM case was loaned to the DARF Center with the femoral head fused to the trunnion. It was therefore an ideal opportunity to evaluate head and cup wear patterns and relate these to their radiographic orientations.

Head wear-patterns were subtended by angles of $106^{\circ}$ and $141^{\circ}$ in the transverse and coronal planes, respectively. This indicated that the patient had not achieved full range of flexion, thought to be due to her posterior impingement. The MWZ centroidal vectors on the head wear pattern were positioned at $18.8^{\circ}$ in the coronal plane and $13.3^{\circ}$ in the transverse plane. The former corresponded well with the average $16^{\circ}$ centroidal-area vector (CA) in the prior retrieval study [31]. Assuming a femoral head at a neutral inclination of $45^{\circ}$ and a femoral stem oriented at $8^{\circ}$ to the vertical, this wear pattern would be orientated $19^{\circ}$ medial to the vertical plane. This corresponded well with biomechanical predictions from gait studies and from instrumented prostheses [36,37]. Following analysis, the head was successfully removed using the appropriate instrumentation.

In this retrieval, much of the stripe wear damage was obscured by stainless steel contamination originating from instrumentation used during revision surgery. Nevertheless the SEM analysis did indicate polar stripe damage indicative of impingement at extremes of hip excursion. This was confirmed by the circumferential neck marking indicative of impingement by the cup rim, these being distinct from damage produced by head removal attempts. The asymmetry in the wear pattern also indicated that impingement had been a habitual occurrence.

The cup with $55^{\circ}$ lateral inclination would not be considered adversely positioned. Nevertheless the wear pattern in the cup was not well contained, i.e. it extended up to the cup rim and circumferentially. Therefore this patient had experienced edge wear during gait and extensive cup thinning was evident, thought to be due to the repetitive subluxation of the femoral head during impingement. Thus there were multiple implant sites capable of releasing metal debris [35]. Trunnion fretting and corrosion aspects are not discussed here, being the subject of a follow-up paper.

In conclusion, this MOM retrieval with a fused head provided confirmation of the manner in which we use wear patterns on heads and cups to deduce implant orientation in vivo. Wear patterns on femoral heads provide a good indication of habitual wear in vivo while cup wear patterns provide insight as to whether the wear was contained centrally in the cup (ideal) or in fact demonstrated adverse edge wear. Implant orientation is also a prerequisite to interpreting significance of stripe damage on heads and whether or 
not it relates to possible cup-to-neck impingement positions creating an edge wear mechanism. This makes stripe analysis possible, even when the femoral stem is not available for inspection.

\section{Disclosure Statement:}

The authors of this article have disclosed that there is no potential for conflict of interest with this work and no benefits or funds were received in support of this paper. For full disclosures refer to last page of this journal.

\section{References}

1. Zahiri CA, Schmalzried TP, Ebramzadeh E, Szuszczewicz ES, Salib D, Kim C, Amstutz HC. Lessons learned from loosening of the McKee-Farrar metal-on-metal total hip replacement. J Arthroplasty 1999;14-3:326-32.

2. Amstutz HC, Grigoris P, Dorey FJ. Evolution and future of surface replacement of the hip. J Orthop Sci 1998;3-3:169-86.

3. Amstutz HC, Le Duff MJ, Harvey N, Hoberg M. Improved survivorship of hybrid metal-on-metal hip resurfacing with second-generation techniques for Crowe-I and II developmental dysplasia of the hip. J Bone Joint Surg Am 2008;90 Suppl 3:12-20.

4. Daniel J, Ziaee H, Kamali A, Pradhan C, Band T, McMinn DJW. Ten-year results of a double-heat-treated metal-on-metal hip resurfacing. J Bone Joint Surg Am 2010;92B:20 - 7 .

5. Amstutz HC, Le Duff M, Johnson AJ. Socket position determines hip resurfacing 10-year survivorship. Clinical Orthopaedics and Related Research 2012;470:3127 -33 .

6. Glyn-Jones S, Pandit H, Kwon YM, Doll H, Gill HS, Murray DW. Risk factors for inflammatory pseudotumour formation following hip resurfacing. J Bone Joint Surg Br 2009;91-B:1566-74.

7. Langton D, Jameson S, Joyce T, Hallab N, Natu S, Nargol A. Early failure of metal-on-metal bearings in hip resurfacing and large-diameter total hip replacement. A consequence of excess wear. Journal of Bone and Joint Surgery Br 2010;92B:38 - 46.

8. Hart AJ, Hester T, Sinclair K, Powell JJ, Goodship AE, Pele L, Fersht NL, Skinner $\mathrm{J}$. The association between metal ions from hip resurfacing and reduced T-cell counts. J Bone Joint Surg Br 2006;88-4:449-54.

9. De Smet K, De Haan R, Calistri A, Campbell PA, Ebramzadeh E, Pattyn C, Gill HS. Metal ion measurement as a diagnostic tool to identify problems with metalon-metal hip resurfacing. J Bone Joint Surg Am 2008;90 Suppl 4:202-8.

10. MHRA. Press release: MHRA issues new advice to surgeons about metal-on-metal total hip replacements. Medicines and Healthcare products Regulatory Agency, 2012.

11. Shimmin AJ, Walter WL, Esposito C. The influence of the size of the component on the outcome of resurfacing arthroplasty of the hip. Journal of Bone and Joint Surgery BR 2010;92 -B:469 - 76.

12. Griffin WL, Nanson CJ, Springer BD, Davies MA, Fehring TK. Reduced articular surface of one-piece cups. A cause of runaway wear and early failure. Clin Orthop Relat Res 2010;468:2328 - 32.

13. Murray D, Grammatopoulos G, Gundle R, Gibbons CL, Whitwell D, Taylor A, Glyn-Jones S, Pandit HG, Ostlere S, Gill H, Athanasou NA, McLardy-Smith P. Hip resurfacing and pseudotumour. ISSN 2011:279 -83.

14. Langton DJ, Sprowson AP, Joyce TJ, Reed M, Carluke I, Partington P, Nargol AV. Blood metal ion concentrations after hip resurfacing arthroplasty: a comparative study of articular surface replacement and Birmingham Hip Resurfacing arthroplasties. J Bone Joint Surg Br 2009;91-10:1287-95.

15. Morlock MM, Bishop NE, Zustin J, Hahn M, Ruther W, Amling M. Modes of Implant Failure After Hip Resurfacing: Morphological and Wear Analysis of 267 Retrieval Specimens. J Bone Joint Surg Am 2008;90:89 -95.

16. Mellon SJ, Kwon YM, Glyn-Jones S, Murray DW, Gill HS. The effect of motion patterns on edge-loading of metal-on-metal hip resurfacing. Medical Engineering \& Physics 2011;33:1212 - 20.

17. Kwon YM, Mellon SJ, Monk P, Murray DW, Gill HS. In vivo evaluation of edgeloading in metal-on-metal hip resurfacing patients with pseudotumours. Bone Joint Res. 2012;1-4:42 -9.
18. Underwood RJ, Zografos A, Sayles RS, Hart A, Cann P. Edge loading in metal-onmetal hips: low clearance is a new risk factor. J Eng in Med 2012;226-3:217 - 6 .

19. De Haan R, Pattyn C, Gill HS, Murray DW, Campbell PA, De Smet K. Correlation between inclination of the acetabular component and metal ion levels in metalon-metal hip resurfacing replacement. J Bone Joint Surg Br 2008;90-10:1291-7.

20. McKellop HA, Campbell P, Park SH, Schmalzried TP, Grigoris P, Amstutz HC, Sarmiento A. The origin of submicron polyethylene wear debris in total hip arthroplasty. Clin Orthop 1995-311:3-20.

21. McKellop HA, ed. Distinguishing among wear modes, wear mechanisms and wear damage in prosthetic joints. 2011:103 - 13.

22. Shishido T, Clarke IC, Williams P, Boehler M, Asano T, Shoji H, Masaoka T, Yamamoto K, Imakiire A. Clinical and simulator wear study of alumina ceramic THR to 17 years and beyond. J Biomed Mater Res 2003;67B-1:638-47.

23. Tateiwa T, Clarke IC, Pezzotti G, Sedel L, Kumakura T, Shishido T, Yamamoto K. Surface micro-analyses of long-term worn retrieved "Osteal (TM)" alumina ceramic total hip replacement. Journal of Biomedical Materials Research Part BApplied Biomaterials 2007;83B-2:562-70.

24. Dorlot JM, Christel P, Meunier A. Wear analysis of retrieved alumina heads and sockets of hip prostheses. J Biomed Mater Res 1989;23-A3 Suppl:299-310.

25. Nevelos JE, Ingham E, Doyle C, Fisher J, Nevelos AB. Analysis of retrieved alumina ceramic components from Mittelmeier total hip prostheses. Biomaterials 1999;20-19:1833-40.

26. Walter WL, Insley GM, Walter WK, Tuke MA. Edge loading in third generation alumina ceramic-on-ceramic bearings: stripe wear. J Arthroplasty 2004;19-4:40213.

27. Manaka M, Clarke IC, Yamamoto K, Shishido T, Gustafson A, Imakiire A. Stripe wear rates in alumina THR--comparison of microseparation simulator study with retrieved implants. J Biomed Mater Res 2004;69B-2:149-57.

28. McKellop H, Park S, Chiesa R, Doorn P, Lu B, Normand P, Grigoris P, Amstutz H. In vivo wear of 3 types of metal on metal hip prostheses during 2 decades of use. Clinical Orthopaedics and Related Research 1996;329S:128 - 40.

29. Glyn-Jones S, Roques A, Gill R, Taylor A, Whitwell D, Esposito C, Walter W, Tuke M, Murray D. Metal on metal hip resurfacing arthroplasty-related pseudotumours are associated with increased bearing surface wear, caused by impingement and edge-loading. 56th Annual Meeting of the ORS. 2010:Poster No. 2164.

30. Tuke M, Taylor A, Roques A, Maul C. 3D linear and volumetric wear measurement on artificial hip joints - Validation of a new methodology. Precision Engineering. Elsevier, 2010:777 - 83.

31. Clarke IC, Donaldson TK, Burgett MD, Smith EJ, Bowsher J, Savisaar C, John A, Lazennec JY, McPherson E, Peters CL. Normal and Adverse Wear Patterns Created In-vivo on MOM Surfaces - a retrieval study representing four vendors. In: Metal-on-Metal Total Hip Replacement Devices. (Ed. Kurtz SM, Greenwald SA, Mihalko WM, Lemons JA). ASTM International: West Conshohocken, PA; 2013 STP1560; 157-92.

32. McHugh D, Currier J, Kennedy F, Collier J, Van Critters D. Plastic Deformation from Edge Loading is common on Retrieved Metal-on-Metal Hips and Can Be Predicted with Finite Element Analysis. In: Metal-on-Metal Total Hip Replacement Devices. (Ed. Kurtz SM, Greenwald SA, Mihalko WM, Lemons JA). ASTM International: West Conshohocken, PA; 2013 STP1560; 157-92.

33. Heiner A D, Kruger K M, Tikekar N M, Lannutti J J, Callaghan J J, Brown T D. Uncertainty of Head Orientation on the Trunnion Undermines Reliability of CaseSpecific Retrieval Wear Simulations. 59th Annual Meeting of the ORS. 2013:Poster No. 1027.

34. Bowsher J G, Clarke I C, Williams P A, Donaldson T K. What is a "normal" wear pattern for metal-on-metal hip bearings? J Biomed Mater Res B Appl Biomater 2009; 91 (1): 297-308.

35. Clarke I C, Lazennec J Y, Brusson A, Savisaar C, Bowsher J G, Burgett M, et al. Risk of Impingement and Third-body Abrasion With 28-mm Metal-on-metal Bearings. Clin Orthop Relat Res 2014; 472 (2): 497-508.

36. Bergmann G, Deuretzbacher G, Heller M, Graichen F, Rohlmann A, Strauss J, et al. Hip contact forces and gait patterns from routine activities. J Biomech 2001; 34 (7): 859-71

37. Paul J P. Biomechanics. The biomechanics of the hip-joint and its clinical relevance. Proc R Soc Med 1966; 59 (10): 943-8. 